\title{
El Patrimonio Cultural de la Iglesia*
}

Por Carlos CORRAL SALVADOR**

Cuando se promulgó en Francia en 1905 la Ley del 5 de diciembre sobre la separación de las Iglesias y del Estado, se la presentó como una ley que pretendía una laicidad aséptica que iba a tratar por igual a todas las Iglesias y cultos. A todos - lo mismo a los ministros del culto que a sus instituciones- se les sometía al derecho común.

Curiosamente, sin embargo, suprimidos todos los privilegios a los clérigos, se les sometió a penas especiales en el caso de incumplimiento de la ley, y a las instituciones católicas se les sometió, no a una ley general (auténtico derecho común desde 1901), sino a una legislación especial en realidad discriminatoria. Es decir, que dirigiéndose en general a todos, iba dirigida en especial contra las instituciones y bienes de la Iglesia Católica (1).

Ahora que acaba de promulgarse la Ley del Patrimonio Histórico Español (LPHE) 13/1985, del 25 de junio (BOE del 29), ¿no ocurrirá algo parecido? La LPHE se presenta también con asepticidad; pretende abarcar todos los bienes del Patrimonio Histórico Español y en su universalidad no hace distinción de titularidades. Pero da la casualidad que las escasísimas veces en que se cita a los bienes eclesiásticos o se les silencia elocuentemente de hecho, éstos dan la impresión de verse discriminados.

Recuérdese cómo en declaraciones públicas de las autoridades civiles y en discusiones de cámaras se repetía con insistencia que en la LPHE no se pretendía en manera alguna establecer discriminaciones sectarias.

Sin embargo, la LPHE era necesaria desde que en 1981 se publicó el primer "Proyecto de Ley por el que se regula con carácter general la defensa del Patrimonio Histórico-Artístico Español", presentado en el

* Este estudio se desarrolla en el marco de la Ley del Patrimonio Histórico Español (LPHE).

** Catedrático de la Universidad Complutense.

(1) CORRAL, Carlos, La libertad religiosa en la Comunidad Europea, estudio comparado, Madrid, Instituto de Estudios Políticos (hoy Centro de Estudios Constitucionales), 1973, p. 64 ss. 
Congreso el 14 de septiembre de 1981 (Boletín de las Cortes, núm. 207-1).

En efecto, la propia constitución del Estado de las Autonomías precisaba una matizada distribución de las competencias. También la creciente integración de España en las Organizaciones Internacionales, de manera especial en las europeas occidentales, exigía un acompasamiento de nuestra legislación con la de aquéllas. Y finalmente, la multiplicidad de normas que, arrancando de la Ley del 13 de mayo de 1933. demandaban por estar a veces dispersas una armonización y puesta al día en su conjunto.

\title{
1. EL POR QUE DE UN RECELO
}

Que existe un recelo, lo evidencian las frecuentes manifestaciones por parte del Estado, antes mencionadas, en orden a calmarlo. Que el recelo no puede menos de aflorar con cierta insistencia, entre tranquila y a veces airada, lo patentizan las conclusiones hechas públicas por Delegados Diocesanos de Arte Sacro de toda España al término de las "IV y V Jornadas Nacionales sobre el Patrimonio Cultural de la Iglesia", celebradas en El Escorial en junio de 1984 y 1985 (2).

Pero, ¿de verdad hay motivos serios para ello? Por desgracia los hay ahora como antes, si bien no del mismo calibre.

Al presente todavía se tiene muy en carne viva la actitud oficializada del PSOE en 1979. En febrero de ese año y en el Hotel Velázquez de Madrid, el entonces Secretario General del PSOE, Alfonso Guerra - hoy Vicepresidente del Gobierno - , hacía la presentación del libro "Propuestas culturales del PSOE", dirigida por R. Ballesteros. [Madrid 1978] (ABC del 24), en cuyas páginas se afirmaba:

\begin{abstract}
"La propiedad privada de los bienes constitutivos del Patrimonio artístico y cultural es incompatible con un modelo de sociedad en que los medios de producción hayan pasado a propiedad colectiva. En consecuen. cia, el PSOE en esta segunda fase, procedería a la socialización, autogestionada respecto a la naturaleza del respectivo objeto cultural, de aquellos muebles o inmuebles de propiedad privada que se considere necesario en el marco global de una sociedad socialista."

La propuesta no es meramente abstracta, es enormemente concreta cuando se trata de aplicar al patrimonio de la Iglesia. Así se añade: "el Patrimonio histórico-artístico de la Iglesia será socializado sin exclusión alguna de bienes muebles o inmuebles. En el momento de establecerse la relación de templos y edificios a adscribir al Culto y servicio religiosos, se procuratá que no coincidan con los de mayor significacion histórico-artística".
\end{abstract}

De la trascendencia de las palabras transcritas y de las intenciones subyacentes sobra todo comentario. Más cuando los temores y recelos

(2) Su contenido y crónica véanse en la revista consagrada a recogerla documentación oficial salida de la Conferencia Episcopal o dirigida a la misma junto con las actividades de Dele. gaciones Diocesanas o Regionales en el ámbito cultural del Patrimonio, cual es "Patrimonio Cultural, Documentación-Información" números 2 y 3 (1984 y 1985$)$. Por ahora es anual y sale por mayo. 
parecían apagados ante las seguridades ofrecidas por la Administración tanto en público como ante los miembros de la Comisión Técnica IglesiaAdministración del Estado (en la que participé al menos dos veces como experto invitado bajo el aspecto jurídico), he aquí que el viernes, 19 de septiembre pasado, se emitía a las 11 de la noche el documental informativo "TELEOBJETIVO": El patrimonio Eclesiástico. Historia de un desamor". Lo vimos y no podemos menos de aceptar el calificativo de "libelo" otorgado por el Diario YA (20-IX-85). Fue un amasijo de reportajes sobre hechos lamentables, unos cometidos por eclesiásticos y otros por laicos, que se presentan hilvanados como si éstos fueran cometidos también por aquéllos; eso sí, envueltos en entrevistas troceadas con las autoridades del Ministerio de Cultura y de la Comisión Episcopal.

Con la "Historia de un desamor" que se decía remontar a 50 años - según el subtítulo del comunicado de prensa que lo anunciaba- emergían los antiguos motivos de recelo. Así lo manifestamos en nuestro artículo de ABC (29-0-85, Domingo) "Historia de un desamory una vieja campaña". Resultaba curioso ver que eran los mismos ataques con el mismo ropaje de presunta objetividad. También curiosa y sorprendentemente respondía a ellos una conferencia tenida hace cincuenta años en la Universidad de Verano de Santander por el entonces Decano de la Facultad de Derecho Canónico de la Universidad Pontificia "Comillas" en 1933. Decía -y vale todavía hoy - refiriéndose al Patrimonio Cultural (entonces se llamaba Tesoro Artístico Nacional) de la Iglesia:

"El tesoro artístico nacional. He aquí el vellocino de oro a cuya conquista viene el Gobierno desde unos años a esta parte dirigiendo las más rudas campañas, atribuyéndose con ardoroso celo un derecho de tutela y vigilancia por su conservación, y por fin, declarando inalienables los objetos que le constituyen, se hallen o no destinados al culto público, aunque pertenezcan a las entidades eclesiásticas.

Como si no hubiese sido la lglesia la más fiel custodia del tesoro artístico, como si hubiese apenas otro tesoro artístico que el de la lglesia, como si no estuviéramos lastimados de ver convertidos en montones de escom. bros soberbios monumentos declarados nacionales" (3).

$Y$ con referencia al comportamiento del pasado añadía citando al Marqués de Lozoya (en su artículo Los continuadores de Mendizábal):

\footnotetext{
"En realidad, los decretos de desamortización de Mendizábal (19 de febrero; 5 y 9 de marzo de 1836) dividieron esta ríqueza, ya muy mermada porincendios y saqueos, en tres porciones. Una de ellas, constituida porlas catedrales, las colegiatas, las parroquias, los conventos de monjas y los santuarios que seguían destinados al culto, quedó en poder de la Iglesia. Otra parte pasó al dominio directo del Estado, y una tercera muy copiosa, fue vendida en pública subasta, y vino a parar en manos de particulares.

Solamente la Iglesia supo conservar la porción de riqueza que permanecía bajo su custodia. Casi todo lo que había en 1836 en los edificios que quedaron destinados al culto, sigue en su lugar y solamente se enajenaba algo, en momentos de extrema penuria, para salvar lo restante. Y sucedía que, cuando algunas monjas que no tenían qué comer vendian un cuadro o
}

(3) REGATILLO, E. F., Concordatos, Santander, Sal Terrae 1933 nn. 152 ss y Concordato español de 1953, Santander, Sal Terrae 1961, cap. V| con ulteriores datos. 
un tapiz, la prensa izquierdista y algunas doctas corporaciones rasgaban sus vestiduras, sin zeparar en el éxodo de las colecciones particulares a extranjero ni en la agonía de los llamados 'Monumentos Nacionales'. Pero, como hemos dicho, estos casos eran raros y hoy, si queremos admirar el Arte Español, es en los templos abiertos al culto donde hemos de buscarto.

Bien distinta fue la suerte de los edificios que quedaron bajo el dominio directo del Estado. Casi al mismo tiempo que salían a la luz las leyes desamortizadoras, se nombraba una junta 'de demolición', encargada de derri bar edificios para ensanchar calles y abrir plazuelas. Los que escaparon de la piqueta fueron convertidos en oficinas públicas y en cuarteles, para sufrir durante un siglo toda suerte de oprobios que acabaron, en muchos casos, en muerte violenta. El que estas líneas escribe recuerda el dolor de una espléndida iglesia ojival condenada sin remisión a servolada con dinamita para utilizar la piedra en cierto edificio militar, y los intentos inútiles para salvar de la demolición unas bellísimas capillas góticas, pertenecientes también al ramo de Guerra.

Casi todas las abadias rurales fueron a parar, con sus cotos redondos, a manos de particulares. Estos edificios eran al poco tiempo montones de ruinas."

Para muestra, al pasar por Burgos o Lerma, desvíese a contemplar, por un lado, a Silos y, por otro, a S. Pedro de Arlanza. Aquél, desamortizado, pero recuperado por los benedictinos conserva su esplendor; éste, no recuperado, sigue mostrando sus grandiosas ruinas (un guarda le podrá ahora acompañar por su interior sin bóvedas: así en el verano de 1985).

Y ya que tanto se alaba la Ley del 13 de mayo de 1933 y su ejemplar cumplimiento lo mismo en el Preámbulo de la LPHE como en el del Proyecto de Ley de 1980, echémosla un vistazo. Es cierto que la regulación de conjunto más amplia vino mediante la Ley de 13 de mayo de 1933 de Defensa, Conservación y Acrecentamiento del Patrimonio HistóricoArtístico Nacional. Pero el sectarismo, que en el fondo latía en aquella Ley, vuelve a aflorar en la subsiguiente Ley de Confesiones y Congregaciones Religiosas, de 2 de junio de 1933, en que a todo el Tesoro Artístico Nacional poseído por aquéllas, se le declara inalienable, se le grava con servidumbres $y$, en último término, se le pone en manos de la Junta de Conservación del Tesoro Artístico (arts. 17 y 18).

Con la guerra civil (1936-39), en la zona de la República que había dictado las anteriores leyes, se procede a la incautación de edificios religiosos por Decreto de 27 de julio de 1936. En el terreno de los hechos y con referencia a dicha zona, al hacer el recuento de las destrucciones, se ha hablado de "Martirio de las cosas"; baste un ejemplo: "Santander: iglesias y ermitas destruidas, 102; iglesias desmanteladas, 175 ; retablos quemados o totalmente destruidos, 765; imágenes quemadas o de otro modo inutilizadas, $3.217^{\prime \prime}(4)$.

(4) MONTERO, A., Historia de la Persecución Religiosa en España 1936-1939, Madrid, BAC, 1961, cap. XXV y p. 636. 


\section{EN QUE AFECTA GRAVEMENTE LA LPHE AL PATRIMONIO CULTURAL DE LA IGLESIA}

Al no establecerse excepciones en la LPHE y comprenderse el "conjunto de bienes que en sí mismos han de ser apreciados, sin establecer limitaciones derivadas de su propiedad, uso, antigüedad o valor económico" (Preámbulo), es claro que intenta comprender los bienes culturales eclesiásticos. De no comprenderlos, ¿para qué la Ley? Nada menos que un 80-85 por ciento de todo el patrimonio cultural español está constituido por aquéllos.

Basten unas cifras aproximadas: los Templos y Casas Rectorales, Parroquiales, Episcopales y Religiosas (unos 70.000) a una con las esculturas, cuadros, tapices, utensilios sagrados... así como los museos (unos 200 ), archivos (sólo los parroquiales sobrepasan los 20.000), bibliotecas (sólo las de seminarios ascienden a unas 130).

Respecto a tan grandioso acervo, la Iglesia (y en su tanto las demás Comunidades religiosas) tiene derecho, reconocido por la Constitución y la Ley Orgánica, a tener garantizada la función social religiosa a que to afectaron.

Por su parte, el Estado, por mor de la Constitución, así como debe cuidar la función cultural que tenga o pueda tener dicho acervo (art. 47), está obligado a garantizar en toda su amplitud el derecho mencionado de libertad religiosa (art. 16).

Ambas legítimas pretensiones, por igual constitucionales, no menos del Estado y de las Administraciones Públicas que de las Iglesias, que de los ciudadanos y de los fieles, al tener que ser garantizadas, plantean de por sí a una ley que aspire a ser justa para ambas comunidades una serie de problemas ineludibles que solventar. Entre ellos descuellan cuatro: el de la afectación del bien religioso de interés cultural a su finalidad religiosa; el de su titularidad conforme a la diversidad y grado de los títulos exhibidos; el de su régimen fiscal, supuesta la actitud de fomento por parte de las Administraciones públicas, y el de la jerarquía de normas que hay que aplicar (en el que todos aquellos problemas revierten en busca de una armónica solución) (5).

\subsection{La función religiosa y el valor cultural}

Quien se acerque a Torremormojón, cerca de su capital palentina, admirará la grandiosa iglesia del s. XVI con su espléndido altar, atribuido a Juan de Flandes, pero no podrá contemplar el Castillo que, encaramado desde el s. XII en el monte, dominaba la villa. El Templo pervive gracias al culto que los fieles de hoy rinden heredado de los padres que lo fundaron.

(5) La misma problemática la tratamos con el Prof. Alberto DE LA HERA en el Congreso de Nápoles celebrado del 26 al 28 de noviembre de 1981 con la ponencia (CORRAL, C., y DE LA HERA, A.). Bienes cuiturales e intereses religiosos en la experiencia europea; España, publi. cada, primero, en Revista Española de Derecho Privado (mayo 1982 pp. 419-440) y, después en el volumen Beni culturali e interessireligiosi, Atti del Convegno di Studi, Napoli 21-28 nov. 1981, Nápoles, ed. Jovene 1983, p. 249 ss. 
Los castellanos, en cambio, se marcharon y el Castillo fue demolido en el siglo XIX.

Desapareció la función esencial de defensa y residencia y, con ella la testimonial de historia y arte. Se mantuvo y se sigue manteniendo la cultual y con ella la cultural de la arquitectura y escultura religiosas. Aquélla es la función social primariạ, ésta es la función social secundaria. Entre ambas funciones sociales lo lógico es que en una ordenación legal sea a la función primaria a la que corresponda la primacía.

Pues bien, hoy con la formación del Estado de Cultura (Kulturstaat), aumenta el intervencionismo de éste y el alargamiento de los objetos de su protección. ¿Cómo armonizar ambas funciones? Las necesidades y consiguientes regulaciones de un edificio militar u hospitalario - aquí de un templo - no necesariamente tienen que coincidir con las del arte o la cultura pura. (Un ejemplo real en Alsacia-Lorena: se trata de reconstruir un templo calvinista de la Iglesia reformada. Las autoridades civiles quieren devolverle su carácter primigenio anterior a la Reforma. Los calvinistas se oponen, pues ello entrañaría convertirlo, con sus características estilísticas, en templo católico. ¿Qué hacer?)

Los legisladores españoles, a pesar de reconocer paladinamente la cuantía del Patrimonio Cultural eclesiástico en los debates parlamentarios, en la LPHE lo tratan exclusivamente bajo la perspectiva de una de las funciones sociales, la cultural. iLástima que no hubieran asumido posiciones doctrinales hoy vigentes en los países de nuestro espacio cultural europeo! He aquí cómo las sintetiza al menos con relación a Alemania W. SCHULZ:

"Al Estado compete indiscutiblemente el derecho de salvaguardar los bienes culturales, en cuanto constituyen un bien de interés público. Al defender este derecho, ha de respetar lo que en el derecho estatal alemán eclesiástico se llama 'la prioridad de los valores culturales' (Kulturwertordnung). A la Iglesia, en cambio compete un interés específico con relación al nung). A la lglesia, en el mantenimiento de las iglesias en cuanto edificios reservados para el culto y el derecho de no ser perturbados durante las funciones religiosas. En el derecho estatal alemán eclesiástico, dicho interés viene llamado la prioridad de los valores del culto (Kultordnung) (6).

Por ello, justamente, la Comisión Episcopal para el Patrimonio Cultural, en su reunión del 25 de marzo de 1985, hace suya la Declaración, preparada por expertos del Patrimonio Cultural de la Iglesia y por representantes del mismo en cada una de las Autonomías. En ella se dice: "Se olvida un elemento integrante de nuestra cultura: su vertiente religiosa. Las mismas manifestaciones religiosas son expresiones básicas de este valor. No se comprende la obsesión laicista de esta ley. El derecho tiene que ser realista" (7).

La misma Iglesia que manda observar las leyes civiles (Sagrada Congregación para el Clero en 1971), exige también el respeto a la función primaria del culto de sus bienes culturales (8).

(6) Beni culturali, cit., p. 240.

(7) En Patrimonio Cultural, cit. en nota 1, 1985.

(8) Sagrada Congregación para el Clero, Carta Circular de 11 de abril de 1971, que sigue en vigor aun después del Código de Derecho Canónico de 1983, n. $^{\circ}$ 4: en Patrimonio Cultural, cit. 1984. 


\subsection{La titularidad del Patrimonio Cultural de la Iglesia y su posible cuestionamiento en la LPHE}

Dado el destino que pueden tener los diversos bienes muebles e inmuebles, sean inventariados, sean catalogados, y el régimen distinto que a través de la Administración del Estado puedan sufrir, hace surgir de forma ineludible la cuestión relativa a la garantía de los titulares de los bienes mencionados.

Esto no deja por lo demás de tener su fuerza en cuanto que se trató por parte de algún parlamentario de atribuir de forma genérica toda la nuda propiedad al Estado, reservando la titularidad de posesión a la Iglesia y sus entidades.

Es cierto que hoy día, tras la transformación de la concepción sobre la propiedad, la titularidad dominical ha pasado a segundo lugar con relación a la afectación cultural, cuando de bienes de interés cultural se trata. Pero no es menos cierto que la experiencia secular -en especial la del s. XIX - dio como resultado que lo trasvasado, primero, a propiedad pública y después a manos privadas, acabó desapareciendo o dispersándose; más aún, en el presente siglo y vigente la Ley de 1933, los templos que fueron nacionalizados en 1936 en la zona republicana fueron convertidos en buena parte en almacenes.

Que es importante para el propio Estado el tener bien garantizada la propia titularidad de los bienes, lo demuestra la reciente Ley 23/1982, de 16 de junio, reguladora del Patrimonio Nacional (BOE 22 jun.). En su artículo $6 .^{\circ}$, n. 2 se manda que "los bienes y derechos integrados en el Patrimonio Nacional (...) deberán ser inscritos en el Registro de la Propiedad como de titularidad estatal".

Después de leer este párrafo, vienen a la memoria los términos vertidos en la LPHE art. 1, que, siendo correctos, al trasluz de lo anterior, pueden prestarse a ambigüedades:

"Integran el Patrimonio Histórico Español los inmuebles y objetos muebles de interés artístico, histórico, paleontológico, arqueológico, etnográfico, clentífico o técnico. También forman parte del mismo el patrimonio documental y bibliográfico, los yacimientos y zonas arqueológicas así como los sitios naturales, jardines y parques que tengan valor artístico, histórico o antropológico".

En este sentido cobran su valor las palabras pronunciadas por el anterior Secretario General de la Conferencia Episcopal, a raíz de la firma de los Acuerdos entre el Estado Español y la Santa Sede en la Universidad "Comillas" el 25 de enero de 1980.

"Si el buen sentido nos ayuda a establecer una jerarquía de derechos - ha escrito recientemente el actual Secretario del Episcopado español-. los bienes del patrimonio serán en su comienzo de aquel a quien deben su existencia, porque los creó o los pagó al artista para sí. No es lícito olvidar. en un planteamiento político realista, que el atentado contra este derecho original de propiedad daría al traste con el estímulo de creación: Nadie manda producir riqueza o belleza en beneficio del que la expolie primero. La voluntad de construir o poseer está orientada por la voluntad de usar con 
algún destino concreto. En el caso de la Iglesia, el patrimonio se crea para las necesidades del culto. El atentado al uso, la desviación del sentido cultural a otros valores estéticos arrancados de él, cegarían, igualmente, las fuentes del arte..." (9).

\subsection{Régimen jurídico de los bienes culturales de la Iglesia y jerarquía de normas}

Todos los problemas apuntados - a los que hay que añadir el fiscal y el administrativo-, si tienen importancia es, ante todo, por la repercusión e incidencia que sobre el uso, destino, enajenación, expropiación y disfrute puedan ejercer las distintas autoridades y funcionarios de las Administraciones públicas. Pues a ellos va referido primordial y casi exclusivamente cuanto se prescribe en la LPHE - es lógico- y sin distinción de clases de bienes ni de titularidades, incluso olvidándose de los titulares legítimos y multiseculares.

Pero sobre todo pesa sobre los bienes inmuebles "declarados de interés cultural", de titularidad eclesiástica, la amenaza de una expropiación. En efecto, en el art. 36 se impone una obligación de conservarlos, mantenerlos y custodiarlos por sus propietarios o, en su caso, por los titulares de derechos reales como los poseedores de tales bienes $\left(n .{ }^{0} 1\right)$. Se imponen unas actuaciones, mientras que la Administración competente podrá ordenar su ejecución subsidiaria, y podrá o no conceder una ayuda. Es decir, pura discrecionalidad. En cambio, el incumplimiento será causa de interés social para la expropiación $\left(n .^{\circ} 3\right)$

Respecto a la expropiación, no se hace alusión a la obligación internacional asumida en el Acuerdo con la Santa Sede sobre Asuntos Jurídi$\cos (\operatorname{art}, 1,5$ y 6$)$.

En el artículo $28, n 0^{\circ} 1$, por un lado, se impone una restricción a los bienes culturales de la Iglesia ("no podrán cederse por título oneroso o gratuito ni cederse a particulares ni a entidades mercantiles. Dichos bienes sólo podrán ser enajenados o cedidos al Estado, a entidades de Derecho Público 0 a otras instituciones eclesiásticas"). Es decir se les atribuye un régimen especial.

Dicha limitación tendría razón de ser, si dichos bienes o la función cultural, inherente a los mismos, tuvieran en la LPHE la consideración de interés (y/o público, al modo del ordenamiento alemán). Pero, si implícitamente -ya que no explícitamente- se les aplica esta consideración en lo odioso, entonces, en justa y buena lógica, habría que aplicársela también en lo ventajoso de otros regímenes como los de fiscalidad, fundaciones, donaciones, museos y archivos por analogía con los equivalentes de titularidad pública. En caso contrario, se está cometiendo una discriminación que podría seguramente provocar un recurso de inconstitucionalidad.

Estos y otros problemas se pueden reconducir en último término al problema de la jerarquía de normas que al respecto deban aplicarse, en

(9) IRIBARREN, J., p. 574 en CORRAL-ECHEVERRIA, cit. nota 9. 
cuanto vayan o puedan ir referidas a los bienes de interés cultural bajo titularidad eclesial. Es lo que trataremos en el siguiente epígrafe.

\section{3. ¿POR QUÉ PUEDE QUEDAR LESIONADA UNA OBLIGACION INTERNACIONAL SOBRE EL PATRIMONIO CULTURAL DE LA IGLESIA?}

Respecto a éste existe en principio una regulación pacticia reflejada en los Acuerdos del Estado Español con la Santa Sede de 3 de enero de 1979 (BOE dic. 79) que son, como recuerda el Tribunal Constitucional (Sentencia, 12 nov. 1982: BOE 10 dic.), de carácter internacional. A ella se llegó porque a juicio de ambas partes, se necesitaba un tratamiento especial que tuviera en cuenta la magnitud, antigüedad, complejidad y vida pujante de un patrimonio eclesiástico que resultaba ser el de mayor vía artística e histórica.

En la LPHE ise respetan en su integridad las normas de dichos Acuerdos y se observa la jerarquía que les corresponde como normas internacionales?

\subsection{Compromisos asumidos por el Estado en sus Acuerdos con la Santa Sede (10)}

De entre éstos, hay dos que directamente afectan a las disposiciones de la Ley del PHE: el uno es el Acuerdo sobre Enseñanza y Asuntos Culturales de forma general y el otro es el Acuerdo sobre Asuntos Jurídicos de forma particular.

El Acuerdo sobre Enseñanza y Asuntos Culturales, de entrada, enuncia el principio de colaboración en el Preámbulo de la siguiente manera:

"El patrimonio histórico, artístico y documental de la Iglesia sigue siendo parte importantísima del acervo cultural de la nación; por lo que la puesta de tal patrimonio al servicio y goce de la sociedad entera, su conservación e incremento, justifican la colaboración de la lglesia y el Estado."

En consecuencia se establece una Comisión Mixta (art. XV):

“La lglesia reitera su voluntad de continuar poniendo al servicio de la sociedad su patrimonio histórico, artístico y documental, y concertará con el Estado las bases para hacer efectivos el interés común y la colabo-

(10) Véase el texto y comentario en CORRAL C. - ECHEVERRIA, L. Los Acuerdos entre la Iglesia y España, Madrid, BAC 1980, capítulos XIX y XX respectivamente.

Sobre el tema véase: ALDANONDO, I., La lglesia y los bienes culturales: Revista Española de Derecho Canónico (1983) 51 ss.; CORRAL, supra nota 2.

FERNANDEZ CATON. J. M., El patrimonio cultural de la lglesia en España y los Acuerdos entre el Estado Español y la Santa Sede, León 1980, p. 16 ss. y Arte Sacro y Patrimonio Artístico de la Iglesia en España (separata de Análisis e Investigaciones Culturales, núm. 9, Madrid, 1981); MARTINEZ BLANCO, A., El Patrimonio artístico y documental eclesiástico como parte del patrimonio nacional: Anales de la Universidad de Murcia, curso 1971-72. 
ración de ambas partes con el fin de preservar, dar a conocer y catalogar este patrimonio cultural en posesión de la Iglesia, de facilitar su contemplación y estudio, de lograr su mejor conservación e impedir cualquier clase de pérdidas, en el marco del artículo 46 de la Constitución. A estos efectos y a cualesquiera otros relacionados con dicho patrimonio, se creará una Comisión Mixta en el plazo máximo de un año a partir de la fecha de entrada en vigor en España del presente Acuerdo."

El Acuerdo sobre Asuntos Jurídicos afecta a la LPHE por razón de la especial inviolabilidad garantizada a los lugares sagrados y a los archivos, así como a su titularidad con relación a los procesos de expropiación. Establécese en su artículo 1 n. 5 y 6 :

"Los lugares de culto tienen garantizada su inviolabilidad con arreglo a las leyes. No podrán ser demolidos sin ser previamente privados de su carácter sagrado.

En caso de su expropiación forzosa será antes oída la autoridad eclesiástica competente" (art. 1,5).

"El Estado respeta y protege la inviolabilidad de los archivos, registros y demás documentos pertenecientes a la Conferencia Episcopal Española, a las curias episcopales, a las curias de los superiores mayores de las órdenes y congregaciones religiosas, a las parroquias y a otras instituciones y entidades eclesiásticas" (art. 1, 6).

Del número 5 se siguen al menos unas limitaciones ulteriores, en cuanto normas especiales internacionales, para las disposiciones generales de la Ley (Título IV especialmente los arts. 36 y 37, así como el Título $V$ arts. 42, 43, 45); y el número 6 al Título VII, en especial 49,34 y 5 ; 51,$2 ; 52,2,3$.

Existiendo, pues, una Comisión mixta Iglesia-Estado, para nada se la menciona como tampoco a la Comisión Episcopal para el Patrimonio Cultural, mientras vienen citadas otras varias instituciones como consultivas; ni siquiera para el patrimonio eclesiástico.

\subsection{Rechazo de la mención expresa de los Acuerdos Estado"Santa Sede (11)}

Para salvar los Acuerdos con la Santa Sede del 3 de enero de 1979 y los Acuerdos-Marco surgidos en su desarrollo y reafirmar la voluntad, ciertamente existente y manifiesta de cumplirlos por parte de la Administración, se había ofrecido al entonces Anteproyecto del Gobierno de Ley del PHE y previo acuerdo en el seno de la Comisión Técnica Mixta IglesiaAdministración del Estado, la fórmula de una Adicional, equivalente a la incorporada a la Ley de Reforma Universitaria (12). Pero el mismo día 3 de

(11)CORRAL, C., Incidencia de la legislación internacional en la Ley del Patrimonio Histórico Español en Revista de Derecho Privado (1985) -en prensa.

(12) Para su formulación definitiva, se había trabajado sobre dos redacciones, una del Ministerio de Cuttura, y otra, de la Comisión Episcopal. Ambas coincidían en el fondo, diferían en el matiz. Helas aquí la del Ministerio:

"El Estado Español colaborará en la protección, revalorización y transmisión a las generaciones futuras del Patrimonio Histórico Español en posesión de la lglesia Católica, en consonancia con lo establecido en el Artículo 46 de la Constitución y en conformidad con to previsto en el Artículo XV del vigente Acuerdo con la Santa Sede sobre Enseñanza y Asuntos Culturates de 3 de enero de 1979". 
mayo de 1984, en que se afirmaba dicha voluntad y por parte del Ministerio se aseguraba que dicha proposición Adicional se recogería en el Proyecto que iría a las Cortes, resultó que éste se publicaba en el Boletín de las Cortes Generales.

Se prometió entonces por el Ministerio de Cultura su inserción a través de una propuesta de miembros del partido en el seno de la Comisión del Congreso. Resultó vano todo intento y antes de que se agotara el plazo para presentar enmiendas, los grupos Populary Vasco presentaron enmiendas al respecto matizando la propuesta primigenia (13).

Ninguna proposición fue aceptada como tampoco se hizo proposición oral alguna por el Grupo Socialista conforme se había indicado desde el Ministerio. Así, sin dicha Adicional pasó al Senado. Reformulada la Adicional por senadores de los Grupos Populary Vasco fue rechazada de nuevo. La razón aducida era que no hacía falta una vez que se trataba de Acuerdos Internacionales acogidos como todos los demás, a las garantías de la Constitución.

Al parecer fue una llamada desde Presidencia la que avanzó una solución de compromiso, a saber, la de, por un lado, no citar de forma expresa los Acuerdos del 79 con la Santa Sede y, de otro, reafirmar el compromiso del Estado de cumplir y hacer ejecutar los Acuerdos Internacionales asumidos por él, comprendiendo, por descontado, aquéllos entre éstos (14).

\subsection{Inversión de jerarquías de normas}

El "sin perjuicio de lo dispuesto en la presente Ley" parece ir derecho contra el artículo 96, 1 frase segunda de la Constitución al establecer que "sus disposiciones sólo podrán ser derogadas, modificadas o suspendidas en la forma prevista en los propios tratados o de acuerdo con las normas generales del Derecho Internacional". Esto es, que las normas relativas al Patrimonio Cultural, establecidas en los Tratados Internacio-

La de la Comisión Episcopal: "El régimen jurídico del Patrimonio Histórico Español en posesión de la Iglesia Católica se regirá, en el marco del Artículo 46 de la Constitución, por lo previsto en el Artículo XV del vigente Acuerdo con la Santa Sede".

(13) Decía así la del Grupo Popular:

"En cuanto a los bienes de la lglesia constitutivos del Patrimonio Histórico y Artístico español, se estará dentro del marco de la Constitución, a lo dispuesto en el artículo 15 del acuerdo con la Santa Sede sobre enseñanza y Asuntos Culturales, de 3 de enero de 1979, y a las Disposiciones que se derivan del mismo, en orden a la aplicación conjunta de las normas de la presente Ley.

Sin detrimento de los fines primarios de carácter religioso del Patrimonio de las lglesias y con respecto de los acuerdos existentes, se aplicará, de acuerdo con la lglesia correspondiente, lo dispuesto en esta Ley referente a la conservación, contemplación, estudio, utilización y promoción de su Patrimonio Histórico. Artístico y Cultural".

(14) Aś́ quedó plasmadá la Disposición Adicional $7 .^{\circ}$

"Sin perjuicio de lo dispuesto en la presente Ley, las Administraciones a quienes corres. ponda su aplicación quedarán también SUJETAS a los ACUERDOS INTERNACIONALES váli. damente celebrados por España.

La actividad de tales Administraciones estará asimismo encaminada al cumplimiento de las RESOLUCIONES Y RECOMENDACIONES que, para la protección del PHE, adopten los ORGANISMOS INTERNACIONALES de los que España sea MEMBRO". 
nales, no pueden ser derogadas, modificadas o suspendidas de forma unilateral por el Estado, de consiguiente, por ninguna ley cual es la del PHE. La única forma es, bien por la norma que se haya establecido en el propio Tratado, bien según las normas generales del derecho internacional, en especial las codificadas por la Convención de Viena de 23 de mayo de 1969, ratificada por España el 2 de mayo de 1972.

De ahí que resulte tan incorrecta la formulacción de la Adicional 7.a., pues, la correcta sería exactamente la inversa, a saber, "sin perjuicio de los Acuerdos y Convenios válidamente celebrados por España, la Administración aplicará la Ley del PHE estando previamente sujeta a aqué"los". Y esto es así porque, independientemente de que se afirme, según una parte de la doctrina, la primacía del orden internacional sobre el interno, una vez que haya formado parte del mismo (como se enunciaba en el Proyecto de Constitución española), o, según otra doctrina, por una reserva de competencias o de dureza a favor de las normas internacionales (15).

En conclusión, la tesis mínima que debe sustentarse es que ninguna disposición interna del Estado puede unilateraimente derogar, modificar o suspender una norma de Derecho internacional.

\section{CONCLUSIONES}

Como punto de partida debe asumirse, tanto por parte de los Estados -en especial de los europeos occidentales - como de la Iglesia, la actitud contemporánea tan diversa de la de épocas pasadas. Se ha pasado de una concepción prevalentemente privatista y/o nacional (regionalista) a otra prevalentemente universal de "patrimonio de la humanidad" y de "patrimonio común de Europa". Por ello, una ley que pretenda ser justa y promotora a la vez del PHE debe ajustarse a los derechos y deberes dimanantes de los distintos fines, naturaleza y titulares y beneficiarios del mismo, y a la vez ser estimuladora del arte y de los bienes culturales a crear, conservar y transmitir.

Ahora bien, un patrimonio tan especial por su magnitud, por su valor artístico e histórico, por su función vital religiosa como es el eclesiástico, requiere un tratamiento especial que armonice funciones, competencias, titularidades y finalidades. Por ello se llegó a sentar el principio de una regulación pacticia, como es la que expresa y solemnemente quedó aceptada y convenida en los Acuerdos del Estado Español con la Santa Sede. Una consciente omisión de la misma dentro de una genérica Disposición Adicional resulta cuando menos sospechosa y expuesta a despertar recelos y resquemores.

Más aún, la actual redacción de la Disposición 7.a (acogedora de los Acuerdos internacionales válidamente celebrados por España -entre

(15) CORRAL, cit. en nota 11 más ampliamente. En general, véanse: Estudios sobre el proyecto de Constitución, CED 1978; GONZALEZ CAMPOS, J., Curso de Derecho Internacional Público, Oviedo 1980. T.1., p. 30 ss. y 359 ss. y Comentarios a la Reforma del Título preliminar del Código Civil, Madrid, Tecnos 1977, p. 92 ss.; SERRANO. J.M., Articulo 96, en GARRIDO FALLA, F. (Dir.) Comentarios a la Constitución Española, Madrid, 1985, 2 ed, p. 1352. 
los que se incluyen los concluidos con la Santa Sede-l podría ser razonablemente tildada de inconstitucional por estar en contra, en su literalidad, del art. 96, 1 de la Constitución.

En un futuro inmediato, si se quiere de verdad eliminar toda discriminación respecto del Patrimonio Cultural Eclesiástico y a la vez llegar a una regulación integradora del interés cultural y del interés religioso a nivel de ámbito nacional se precisa lo siguiente:

1. Se hace imprescindible un acuerdo Gobierno (Ministerio de Cultura)-Conferencia Episcopal también a nivel estatal. No se olvide que la LPHE del 85 no conserva el cúmulo de competencias que poseía la Ley de 1933. La mayor parte de éstas se han traspasado a las Comunidades Autónomas, si bien en distintos grados.

2. No se comienza desde cero: existen acuerdos firmados válidamente a dicho nivel como éstos:

- "Documento relativo al marco juridico de actuación mixta IglesiaEstado sobre Patrimonio Histórico Artístico" suscrito, por parte del Gobierno, por el Ministro de Cultura, Sr. Cavero, y, por parte de la Jerarquía Eclesiástica, por el Card. Tarancón, Presidente de la Conferencia Episcopal Española, el 30 de octubre de 1980.

- "Normas con arreglo a las cuales deberá regirse la realización del inventario de todos los bienes muebles e inmuebles de carácter históricoartístico y documental de la Iglesia Españo/a"suscrito, por parte de la jerarquía eclesiástica, por el Presidente de la Comisión Episcopal para el Patrimonio Cultural, Mons. Benavent, y, por parte del Gobierno, por el Subsecretario de Cultura, Sr. Tussel, el 30 de marzo de 1982.

3. Existen a nive/ de Comunidades Autónomas Acuerdos-Marco de actuación conjunta, destacando los de la Generalidad de Cataluña, Castilla-León, Aragón, Galicia e Islas Baleares y otros están próximos a ser firmados y promulgados.

$4 .^{\circ}$ Existe el marco jurídico, representado por la Constitución y su desarrollo, y por los mencionados Acuerdos con la Santa Sede y los Acuerdos surgidos para su desarrollo ya antes citados.

La voluntad por parte de la Iglesia es clara y se mantiene inalterada desde el Acuerdo sobre Enseñanza y Asuntos Culturales del 3 de enero de 1979. La voluntad del Estado consta por manifestaciones, al menos orales, de llegar a un acuerdo específico cultural con los representantes de la Conferencia Episcopal, una vez que no se quiso incluir en una ley de carácter general una excepción de carácter especial.

La verdad es que la muchedumbre de bienes religiosos de interés cultural unida a la de bienes culturales de la nación resulta tan ingente, costosa, laboriosa y permanente que se impone una estrecha colaboración de todas las fuerzas sociales. Ni el Estado solo, ni las Autonomías solas, como tampoco ni la Iglesia ni los particulares solos se bastan.

Sólo de fecundas colaboraciones - como entre la Institución Príncipe de Viana, Arzobispado de Pamplona, Universidad de Navarra y pueblo - pueden brotar obras y catálogos monumentales de auténtica valía. 